\title{
INSTITUIÇÕES, CONFINAMENTO E RELAÇÕES DE PODER: QUESTÕES METODOLÓGICAS NO PENSAMENTO DE MICHEL FOUCAULT
}

\author{
INSTITUCIONES, CONFINAMIENTO Y RELACIONES DE PODER: \\ CUESTIONES METODOLÓGICAS EN EL PENSAMIENTO DE MICHEL \\ FOUCAULT \\ INSTITUTIONS, CONFINEMENT AND POWER RELATIONS: \\ METHODOLOGICAL ISSUES IN THE THOUGHT OF MICHEL FOUCAULT
}

Flávia Cristina Silveira Lemos

Universidade Federal do Pará, Belém/PA, Brasil

Hélio Rebello Cardoso Junior

Universidade Estadual Paulista Júlio de Mesquita Filho, Assis/SP, Brasil

Marcos César Alvarez

Universidade de São Paulo, São Paulo/SP, Brasil

\begin{abstract}
RESUMO
O artigo trata de uma discussão sobre a análise de instituições a partir do pensamento de Michel Foucault. Um dos objetivos é interrogar a afirmação de que Foucault definiu os mecanismos disciplinares como restritos ao confinamento em algumas instituições. Visa-se ressaltar que as relações de poder não eram propriedade de uma instituição ou apenas restritas ao Estado. Busca-se pensar como as tecnologias biopolíticas também extrapolam o âmbito estatal e operam governos das condutas por meio de articulações e composições e não ficam apenas fixadas em uma entidade de maneira naturalizada. Outro ponto tratado é o questionamento realizado por Foucault da visão de poder apenas como repressão e massificação operada pelas instituições. Finaliza-se, apontando a preocupação central de Foucault, qual seja, a análise das práticas, e não apenas das instituições.
\end{abstract}

Palavras-chave: análise de instituições; Michel Foucault; relações de poder.

\section{RESUMEN}

El artículo es una discusión sobre el análisis de las instituciones del pensamiento de Michel Foucault. Uno de los objetivos es cuestionar la afirmación en el que Foucault define los mecanismos disciplinarios como restringido al confinamiento en algunas instituciones. Cuya finalidad es destacar que las relaciones de poder no eran propiedad de una institución o restricta al Estado. En el que busca pensar cómo las tecnologías bio-políticas también extrapolan el ámbito estatal y operan gobiernos de las conductas por medio de articulaciones y composiciones y no quedan apenas fija en una entidad de manera naturalizada. Otro punto relevante es el cuestionamiento hecho por la visión del poder de Foucault apenas como represión y masificación operada por instituciones. Finaliza apuntando la preocupación central de Foucault, , el análisis de las prácticas, no sólo apenas de las instituciones.

Palabras clave: análisis de las instituciones, Michel Foucault, las relaciones de poder.

\begin{abstract}
The article is a discussion on the analysis of institutions from the thought of Michel Foucault. One goal is to interrogate the claim that Foucault's disciplinary mechanisms defined as restricted to confinement in some institutions. The aim is to point out that power relations were not owned by an institution or just restricted to the state. The aim is to think how the biopolitical technologies also surpass the state level by governments and operate the pipeline through the joints and compositions and unfixed in an essential entity. Another point addressed is the questioning conducted by Foucault's vision of power as repression and mass operated by the institutions. Ends pointing to the central concern of Foucault, namely the analysis of practices and not institutions.
\end{abstract}

Keywords: analysis of institutions; Michel Foucault; power relations. 


\section{Introdução}

Pretende-se, neste texto, tecer algumas considerações metodológicas a respeito de como Michel Foucault (1926-1984) problematiza as noções de instituição e de poder ao longo de sua trajetória intelectual, tendo em vista aspectos de suas discussões sobre as disciplinas e a biopolítica como tecnologias de poder. Com frequência, leituras rápidas de textos como Vigiar e punir e O poder psiquiátrico, por exemplo, costumam induzir a crítica de que Foucault teria sido um pensador exclusivamente do confinamento e de que as tecnologias de poder seriam exercidas intramuros, como se poder e instituição fossem elementos inseparáveis.

Tendo em vista indicar a complexidade de tal debate, busca-se ressaltar aqui que as instituições, para Foucault, não são espaços exclusivos de exercícios do poder, mas sim espaços atravessados por tecnologias de poder cuja aplicação não está restrita aos muros institucionais nem às práticas de confinamento.

\section{Do confinamento à sociedade disciplinar}

Já em História da Loucura (Foucault, 1978), Foucault se interessa em acompanhar as mutações dos mecanismos de exclusão social e as práticas institucionais, mas tendo em vista sobretudo o efeito do que posteriormente ele chamará de aspectos "produtivos" dessas tecnologias de poder. Do estudo do grande mecanismo de exclusão da Lepra e das práticas institucionais que tentaram combatê-la, ao longo da Idade Média, até o asilo do final do século XVIII, o que interessa enfatizar são os efeitos mais amplos de tais transformações no conjunto das demais práticas de poder e de saber. Ou seja, já se trata de uma história das práticas de confinamento que não se limita a seus efeitos no interior de determinadas instituições, mas sim que busca acompanhar os efeitos práticos e simbólicos mais amplos da exclusão na sociedade.

Essa intuição básica será reiteradamente retomada em seus escritos. No curso Segurança, território e população, Foucault (2008a) indica explicitamente pistas relevantes para traçar um mapa de como analisava as instituições. A primeira pista implica realizar uma análise que passe para o exterior da instituição, descentrando-a. Como exemplo, Foucault (2008a) afirma que, quando se referiu ao hospital psiquiátrico, já alertava que esse não poderia ser descrito apenas tendo em vista seu interior e as suas atividades internas, pois seria preciso problematizar a própria ordem psiquiátrica e a higiene pública que lhes seriam exteriores.

Desse modo, uma questão metodológica é aberta por ele, ao afirmar que um conjunto de tecnologias de poder não se limita ao interior do asilo. Foucault (2008a) propõe uma análise global das relações de poder, pensando as redes de aliança e de apoio que não se reduzem à descrição de um mundo interno à instituição. Desta feita, o autor propõe metodologicamente que se passe por fora da instituição, indicando que se faça uma análise global das relações de poder. A mesma opção metodológica é manifesta em Vigiar e Punir: "A disciplina não pode se identificar com uma instituição nem com um aparelho; ela é um tipo de poder, ... uma tecnologia" (Foucault, 1999, p. 177). Trata-se de focarse em um extrainstitucional, interrogando as práticas de internamento, de segregação e punitivas por fora da escola, do hospital, do asilo e das prisões.

Duas imagens, portanto, da disciplina. Num extremo, a disciplina-bloco, a instituição fechada, estabelecida à margem, e toda voltada para funções negativas: fazer parar o mal, romper as comunicações, suspender o tempo. No outro extremo, com o panoptismo, temos a disciplina-mecanismo: um dispositivo funcional que deve melhorar o exercício do poder tornando-o mais rápido, mais leve, mais eficaz, um desenho das coerções sutis para uma sociedade que está por vir. O movimento que vai de um projeto ao outro, de um esquema da disciplina de exceção progressiva dos dispositivos de disciplina ao longo dos séculos XVII e XVIII, sua multiplicação através de todo o corpo social, a formação do que se poderia chamar grosso modo a sociedade disciplinar. (Foucault, 1999, p. 173)

Ora, fica explícito na citação de Foucault que o que se generaliza como sociedade disciplinar não é um modelo de instituição asilar, e sim a disciplina como um mecanismo em meio aberto. É a discussão sobre o panoptismo em Vigiar e Punir que abre espaço para a investigação de como os mecanismos de vigilância foram generalizados em meio aberto e desinstitucionalizados em composição e arranjos móveis e dinâmicos, como um diagrama de comunicação intensiva e com várias redes de articulações de visibilidade e de dizibilidade. Jeremy Benthan não teria inventado apenas um modelo de arquitetura no século XIX, e sim uma cartografia da sociedade moderna, de acordo com Foucault.

A disciplina aplicada a corpos sequestrados em instituições, em espaços de isolamento e de segregação não foi uma regra, e sim a exceção de uma sociedade disciplinar. Nesse sentido, Foucault assinala que as relações de poder disciplinares não dependem das instituições de sequestro dos corpos para exercerem 
processos de assujeitamento, o que implica "fim das grades, fim das correntes, fim das fechaduras pesadas" (Foucault, 1999, p. 167).

Se a tentativa de uma determinada forma de controle da lepra suscitou um modelo de exclusão por fechamento e cerca, a disciplina foi a tática para lidar com outro diagrama-acontecimento, o modelo da peste que demandava um policiamento e vigilância detalhados e constantes, funcionando por inclusão e distribuição das multiplicidades a serem geridas extramuros. Mas, como se explica que as práticas de poder atravessam as instituições disciplinares em mão dupla, tornando contínuos o intramuros e o extramuros das mesmas?

A disciplina é uma tecnologia que é usada para fins maciços e serve para funções precisas em instituições (casas de detenção, exército, escola, hospital, polícia). Essa expressão foi usada por Foucault (1999) em Vigiar e Punir porque trazia uma dimensão de intensidade e de acirramento de práticas de aumento da produtividade concomitantes com a criação de docilidade política. Essas instituições são espaços disciplinares, pois uma das características básicas da tecnologia disciplinar é que ela tem como condição, para moldar certa multiplicidade de corpos de acordo com uma determinada função, que a multiplicidade de corpos seja restrita e que o espaço seja limitado, não muito extenso. Sendo assim, a disciplina não está contida em nenhum desses espaços institucionais. A disciplina é uma relação de poder que se atualiza em cada um desses espaços, com seus enunciados e visibilidades próprios. Justamente aí reside uma das especificidades da disciplina: ela articula vários espaços, aumentando seu poder de propagação e alcance.

Então, a sociedade disciplinar se organiza de acordo com a contigüidade de vários espaços disciplinares, onde funções, embora diferentes entre si quanto a seu objetivo, se interconectam no sentido de que obedecem ao mesmo diagrama ou organização. Dessa forma, o ideal da sociedade disciplinar é maximizar o exercício da função em cada espaço para que as várias funções disciplinares se encadeiem sem lacunas. A sociedade disciplinar também precisa aumentar os espaços disciplinares, a fim de que o deslocamento dos indivíduos entre os vários espaços não interrompa a continuidade da normalização.

\section{Do poder disciplinar ao governo das condutas}

Costuma-se considerar que as análises desenvolvidas por Michel Foucault em seus cursos no Collège de France no final dos anos 70 do século XX buscam refinar sua noção de poder e ao mesmo tempo responder a dois conjuntos de críticas feitas à abordagem que havia desenvolvido em Vigiar e Punir. A primeira, de que sua microfísica do poder não seria capaz de dar conta dos processos de subjetivação, ou seja, de que mesmo as práticas disciplinares envolveriam tanto subjugação quanto formas de autossubjetivação; a segunda, a insuficiência de sua análise das instituições disciplinares modernas, como o hospital e a prisão, já que a emergência de tais instituições seria dependente da formação do Estado moderno (cf. Lemke, Krasmann, \& Bröckling, 2011, pp.1-2).

Essa é uma pista interessante para entender por que Foucault (2008a, 2008b) irá enfrentar, a partir de então, a questão do Estado, mas adotando a precaução metodológica de que não se trata de fazer uma análise geral, forjando uma unidade entre o local e o global na figura da presença totalizadora do Estado. Foucault (2008a) continuará questionando a visão de que as relações de poder seriam uma propriedade estatal e/ou estariam centralizadas no Estado.

O conceito de governo das condutas no plano micro e macro não se limita à ação estatal, pois há múltiplas formas de governar e elas se imbricam, contudo, sem totalização. Um Estado é uma realidade compósita e móvel (Foucault, 2008a, 2008b), assim como seu processo de governamentalização tem uma história ainda recente e que o governo das condutas é realizado também por professores, pelos pais, por um chefe, por um vizinho, por um terapeuta, não apenas por um órgão, instituição ou qualquer entidade abstrata.

Se em Vigiar e Punir Foucault definia o poder sobretudo em termos de táticas, tecnologias, estratégias, os desdobramento posteriores de sua análise o levarão a definir o poder também em termos de "um modo de ação sobre a ação dos outros" ou seja, "o "governo" dos homens uns pelos outros (Foucault, 1995, p.244). Mais uma vez, os efeitos dessa posição demandam a desfuncionalização e a desinstitucionalização das relações de poder num quadro em que agora o Estado aparece não mais como uma simples ilusão mas como o efeito histórico de práticas complexamente articuladas de governo de indivíduos e de populações. A ênfase recai assim sobre processos de estatização de práticas e de extensão do governo das condutas.

Novamente, trata-se de pensar na mobilidade das relações de poder e não em sua estrutura rígida, analisando acontecimentos singulares, laterais, locais, diagonais e em captura em dispositivos provisórios concentradores de lutas díspares que se conectam 
e produzem um efeito geral de conjunto. Como exemplo, o autor destaca que foi importante passar por trás do hospital para analisar a biopolítica, que não se restringia ao Estado, contudo, passava por ele, porém sem limitar o governo da vida a este, pois, a gestão da vida extrapolava o hospital e o Estado na medida em que resultava de um racismo de sociedade também (Foucault, 1999).

Se o governo das condutas aparece como preocupação em gerir a minúcia nas técnicas disciplinares; na biopolítica, governar era dirigir as condutas da população de modo geral. Vale ressaltar que tanto a disciplina quanto a biopolítica são formas de gestão da multiplicidade e não práticas de massificação (Foucault, 1988, 1999). Não há para Foucault um sujeito individual ou coletivo enquanto essência que seria impedido de se manifestar por uma espécie de poder como repressão de uma identidade original violada e degradada.

\section{Instituições e repressão}

Em O poder psiquiátrico, Foucault (2006) postula uma problematização que não se centraliza na instituição psiquiátrica, voltando-se para as relações de força que perpassam as instituições. A noção de instituição como objeto prévio é vista como complicada, pois ela remete ao funcionalismo e às análises de regularidades funcionais de um suposto coletivo. Também questiona a análise institucional que se propõe a pensar a instituição como um microcosmo e uma totalidade autônoma, a partir de uma análise etnográfica da mesma. Esse tipo de noção se relaciona a uma lógica de oposição entre dentrofora e de confinamento-saída dos muros. Foucault não propõe uma reforma das instituições e sim uma desfuncionalização das relações de poder com uma correlata desinstitucionalização.

Em discussão paralela, Foucault (1979) interrogava uma análise das instituições como interpretação de algo oculto por um processo de repressão seja de um suposto inconsciente, seja de uma repressão social ou como efeito de uma infra-estrutura econômica. Rejeitava ainda a analítica freudomarxista que teria sido difundida como modo de análise do poder enquanto algo reprimido a ser liberado.

A noção de ideologia me parece dificilmente utilizável, ... ela está sempre em oposição virtual a alguma coisa que seria a verdade. ... A noção de repressão por sua vez é mais pérfida. Ora, me parece que a noção de repressão é totalmente inadequada para dar conta do que existe justamente de produtor no poder. Quando se define os efeitos de poder pela repressão, tem-se uma concepção puramente jurídica deste mesmo poder; identifica-se o poder a uma lei que diz não. $\mathrm{O}$ fundamental seria a força da proibição. Ora, creio ser esta uma noção negativa, estreita e esquelética do poder que curiosamente todo mundo aceitou. (Foucault, 1979, pp. 7-8)

Todas essas discussões nos permitem enfatizar o deslocamento analítico realizado por Foucault, em um campo de debates das décadas de sessenta a oitenta do século XX formado pelas diferentes correntes da análise institucional: psicoterapia institucional, psicossociologia, comunidades terapêuticas, socioanálise, psiquiatria de setor, antipsiquiatria, psiquiatria democrática e a análise das instituições asilares.

Foucault promove uma inflexão no movimento institucionalista por rejeitar os postulados freudomarxistas que ancoravam algumas das correntes do institucionalismo, como as que localizavam o poder no Estado e/ou na instituição; as que utilizavam as noções de um encoberto institucional; as que trabalhavam com uma perspectiva dialética entre instituinte e instituído.

Também interrogava as vertentes que pretendiam reformar o hospital e gerir as relações humanas em seu interior e/ou difundi-lo/generalizá-lo para toda a sociedade. Desse modo, Foucault (2008b) critica como grande parte das análises de poder ainda foca o Estado como se ele fosse uma entidade unitária e se expressasse enquanto um monstro frio. $\mathrm{O}$ autor questiona que os conceitos de poder como totalitarismo e autoritarismo que têm sido utilizados como crivo para qualquer ação estatal não seriam válidos para interrogar todas as práticas de gestão das populações.

"O uso da noção de repressão como carro-chefe da crítica política fica viciado, prejudicado de antemão pela referência - jurídica e disciplinar - à soberania e à normalização" (Foucault, 1979, p. 191).

Nesse sentido, é problematizada a ideia de recalque institucional e de conflitos sexuais ocultos nas instituições como efeito de um processo de alienação a ser destravado e contestado. Foucault (1988) afirma que revelar o segredo de uma sexualidade supostamente reprimida foi toda uma estratégia biopolítica, pois, há uma incitação em tratar das questões referentes à sexualidade nas sociedades capitalistas e burguesas por meio de uma promessa de liberação sexual e político-econômica.

Alguma coisa da ordem da revolta, da liberdade prometida, da proximidade da época de uma nova lei, passa facilmente nesse discurso sobre a opressão do sexo. Certas velhas funções tradicionais da profecia 
nele se encontram reativadas. Para amanhã o bom sexo. É porque se afirma essa repressão que se pode ainda fazer coexistir, discretamente, o que o medo do ridículo ou o amargor da história impedem a maioria dentre nós de vincular: revolução e felicidade; ou, então, revolução e um outro corpo, mais novo, mais belo; ou, ainda, revolução e prazer. Falar contra os poderes, dizer a verdade e prometer o gozo; vincular a iluminação, a liberação e a multiplicação de volúpias; empregar um discurso onde confluem o ardor do saber, a vontade de mudar a lei e o esperado jardim das delícias - eis o que, sem dúvida, sustenta em nós a obstinação em falar do sexo em termos de repressão; eis também, o que explica, talvez, o valor mercantil que se atribui não somente a tudo o que dela se diz como, também, ao simples fato de dar atenção àqueles que querem suprimir seus efeitos. Afinal de contas, somos a única civilização em que certos prepostos recebem retribuição para escutar cada qual fazer confidência sobre seu sexo. (Foucault, 1988, p. 13)

Pois se o poder só tivesse a função de reprimir, se agisse apenas por meio da censura, da exclusão, do impedimento, do recalcamento, à maneira de um grande super-ego, se apenas se exercesse de um modo negativo, ele seria muito frágil. ... O poder, longe de impedir o saber, o produz. (Foucault, 1979, p. 148)

Foi estabelecida uma relação entre saúde e confissão para liberação sexual como proposta de análise das instituições que passa pelo âmbito da produção de saberes, do que Foucault (1988) nomeou uma vontade de saber. Para expandir a vida passouse a buscar uma decifração dos supostos segredos da sexualidade reprimida e colocar o sexo em discurso como estratégia frente a um Estado pensado como figura opressora. Contudo, é justamente quando se afirma que o sexo é impedido é que se prolifera uma incitação política a se falar sobre os comportamentos sexuais: levantamentos de taxas de natalidade, de mortalidade, de contágio por doenças, de fecundidade, idade para o casamento, precocidade das relações sexuais, modos de contracepção, freqüência das relações sexuais, nascimentos legítimos ou não e planejamento familiar. A conduta sexual da população entra em um regime de gestão da vida.

Ora, mas essa preocupação extrapola as práticas de controle realizadas pelo Estado. Organizações não-governamentais, fundações, entidades civis, pesquisadores, psicólogos, médicos, juristas, antropólogos passam a demandar intervenções sobre a gestão da vida pelo controle sexual como modo de proteção e defesa da sociedade.

Criaram-se em todo canto incitações a falar; em toda parte, dispositivos para ouvir e registrar, procedimentos para observar, interrogar e formular. ...
Do singular imperativo, que impõe a cada um fazer de sua sexualidade um discurso permanente, aos múltiplos mecanismos que, na ordem da economia, da pedagogia, da medicina e da justiça incitam, extraem, organizam e institucionalizam o discurso do sexo, foi imensa a prolixidade que nossa civilização exigiu e organizou. (Foucault, 1988, p. 39)

\section{Estado e instituições}

Logo, Foucault não pretendia, como muitos teóricos institucionalistas, encontrar o Estado por trás de todas as instituições como uma alma absoluta. Quando Foucault assinala que ainda não cortamos a cabeça do rei ele desejava apontar como as análises de poder, no século XX giravam ainda em torno da soberania política e das teorias contratualistas. "É preciso estudar o poder colocando-se fora do modelo do Leviatã, fora do campo delimitado pela soberania jurídica e pela instituição estatal" (Foucault, 1979, p. 186). Em Nascimento da Biopolítica, Foucault (2008b) ressalta como o governo das condutas da população extrapola a gestão estatal, sendo uma maneira não apenas de gerar saúde, mas uma regulação aberta de controle de comportamentos por cálculos de risco.

O próprio Estado é uma composição de interesses e intrigas em perpétuo deslocamento e que age em combinação com organizações nãogovernamentais, de maneira a relacionar-se com ações não-estatais articuladas aos saberes, em um Complexo de tecnologias de regulação da vida em meio-aberto.

Não há, portanto, integração do Estado ao Império. O Estado só existe como os Estados, no plural. ... O Estado não é um monstro frio, é o correlato de uma certa maneira de governar. E o problema está em saber como se desenvolve essa maneira de governar, qual a sua história, como ela ganha, como ela inventa, forma, desenvolve novas práticas - é esse o problema, e não fazer do [Estado], como no teatro dos fantoches, uma espécie de policial que viria reprimir as diferentes personagens da história. (Foucault, 2008b, pp. 7-9)

Interessa ao genealogista deter-se no estudo das relações de sujeição recíprocas e múltiplas, materializadas em práticas concretas e não partir da centralização das mesmas no rei, no soberano, na burocracia, na instituição e no Estado. Em Nascimento da Biopolítica (2008b), Foucault destaca que prefere estudar as relações de poder em um campo mais amplo de tensões e disputas que atravessam o Estado governamentalizado sem se restringir a ele e a um conjunto de instituições específicas.

Neste trabalho sobre as prisões, assim como em outros, o alvo, o ponto de ataque da análise, eram não 
as "instituições", não as “teorias" ou uma "ideologia”, mas as "práticas" - e isto para captar as condições que, em um dado momento, as tornam aceitáveis: a hipótese sendo a de que os tipos de práticas não são apenas comandados pela instituição, prescritos pela ideologia. (Foucault, 2006, pp. 337-338)

“O poder não é uma instituição e nem uma estrutura, não é uma certa potência de que alguns sejam dotados: é o nome dado a uma situação estratégica complexa numa sociedade determinada" (Foucault, 1988, p. 103).

A apropriação polêmica do livro Vigiar e Punir, de Foucault (1999) teria difundido uma visão de que o autor teria feito uma análise das prisões, das escolas, das fábricas e de outras instituições, todavia, ele nega que tenha se preocupado exclusivamente com as instituições e assinala que havia interrogado sobretudo as práticas punitivas, apontando que estas atravessavam as prisões também sem se restringirem a elas. Ora, o foco, então, era a análise de práticas enquanto maneiras de fazer.

É preciso construir uma analítica do poder que não tome mais o direito como modelo e código. ... O poder, de fato, não regeu a sexualidade ao modo da lei e da soberania. ... Pensar, ao mesmo tempo, o sexo sem lei e o poder sem o rei. ... a análise em termos de poder não deve postular, como dados iniciais, a soberania do Estado, a forma da lei ou a unidade global de uma dominação; estas são apenas e, antes de mais nada, suas formas terminais. (Foucault, 1988, pp. 100-103)

Não interessava a Foucault analisar se o poder era legítimo ou não, nem partir do quadro dos Direitos Humanos em termos de ligação com a soberania jurídica e estatal para problematizar as formas de governo da população. Foucault (2008b) afirma que não pretendia partir do Direito e sim da própria prática governamental, desse modo, a prática governamental difere do sistema jurídico dos direitos humanos apesar de coexistir com ele e com uma série de elementos heterogêneos.

Mas se, em compensação, dizer "renunciar a fazer uma teoria do Estado" significa não começar por analisar em si e por si a natureza, a estrutura e as funções do Estado, se renunciar a fazer uma teoria do Estado quiser dizer não procurar deduzir, a partir do que é o Estado como uma espécie de universal político e, por extensão, o que pode ter sido o estatuto dos loucos, dos doentes, das crianças, dos delinqüentes, etc., numa sociedade como a nossa, então, responderei: sim, claro, a essa forma de análise estou decidido a renunciar. Não se trata de deduzir todo esse conjunto de práticas do que seria a essência do Estado em si mesma e por si mesma. É preciso renunciar a tal análise, primeiro, simplesmente porque a história não é uma ciência dedutiva, segundo, por outra razão mais importante, sem dúvida, e mais grave: é que o Estado não tem essência. $\mathrm{O}$ Estado não é um universal, o Estado não é em si uma fonte autônoma de poder. O Estado nada mais é que o efeito, o perfil, o recorte móvel de uma perpétua estatização, ou de perpétuas estatizações, de transações incessantes que modificam, que deslocam, que subvertem, que fazem deslizar insidiosamente, pouco importa, as fontes de financiamento, as modalidades de investimento, os centros de decisão, as formas e os tipos de controle, as relações entre as autoridades locais, a autoridade central, etc. Em suma, o Estado não tem entranhas, como se sabe, não só pelo fato de não ter sentimentos, nem bons nem maus, mas não tem entranhas no sentido de que não tem interior. $O$ Estado não é nada mais que o efeito móvel de um regime de governamentalidades múltiplas. É por isso que eu me proponho analisar essa angústia do Estado, essa fobia do Estado, que me parece um dos traços característicos de certas temáticas correntes na nossa época. Ou antes, proponho-me retomá-la e testá-la, mas sem procurar arrancar do Estado o segredo do que ele é, como Marx tentava arrancar da mercadoria o seu segredo. Não se trata de arrancar do Estado o seu segredo, trata-se de passar para o lado de fora e interrogar o problema do Estado, de investigar o problema do Estado a partir das práticas de governamentalidade. (Foucault, 2008b, pp. 105-106)

A biopolítica e a disciplina não são mecanismos exercidos diretamente pela figura do Estado e das instituições, por isso, Foucault assinalou aos seus interrogadores: "vou renunciar a fazer uma teoria do Estado, assim como podemos e devemos renunciar a um almoço indigesto" (Foucault, 2008b, p. 105). No mesmo sentido, ele recusaria uma teoria das instituições. No entanto, ao renunciar, em ambos os casos, a fazer uma teoria, não se tratava de abrir mão de explicar os amplos processos de estatização e de institucionalização que caracterizam a modernidade mas sim de não deduzir tais processos a partir de uma entidade universal ou autônoma de poder. Também não reduzir cadeias complexas de acontecimentos históricos a alguns de seus "nós", quer seja o Estado, quer sejam as instituições. Assim, numa das inúmeras vezes em que foi indagado acerca do modo como deveria ser analisada a relação de poder, Foucault responde:

Não se trata de negar a importância das instituições na organização das relações de poder. Mas de sugerir que é necessário, antes, analisar as instituições a partir das relações de poder, e não o inverso; e que o ponto de apoio fundamental destas, mesmo que elas se incorporem e se cristalizem numa instituição, deve ser buscado aquém. (Foucault, 1995, p. 245) 
Em suma, não se trata, em Foucault, de abrir mão totalmente de uma análise das instituições mas sim, ao evitar as ciladas de partir de uma teoria que permitiria deduzir o que é acaso e necessidade, de abrir espaços para novas formas de problematização e de ação em relação a práticas de poder sempre in fieri.

\section{Referências}

Foucault, M. (1978). História da Loucura. São Paulo: Perspectiva.

Foucault, M. (1979). Microfisica do poder. Rio de Janeiro: Graal.

Foucault, M. (1988). História da sexualidade I: a vontade de saber. Rio de Janeiro: Graal.

Foucault, M. (1995). O sujeito e o poder. In H. L. Dreyfus \& P. Rabinow (Orgs.), Michel Foucault: uma trajetória filosófica: para além do estruturalismo e da hermenêutica (pp. 231249). Rio de Janeiro: Forense Universitária.

Foucault, M. (1999). Vigiar e punir: a história da violência nas prisões. Petrópolis, RJ: Vozes.

Foucault, M. (2006). O poder psiquiátrico. São Paulo: Martins Fontes.

Foucault, M. (2008a). Segurança, território e população. São Paulo: Martins Fontes.

Foucault, M. (2008b). Nascimento da Biopolítica. São Paulo: Martins Fontes.

Lemke, T., Krasmann, S., \& Bröckling, U. (2011). Governmentality: Current issues and futures challenges. New York: Routledge.

Submissão em: 27/03/2011

Revisão em: 04/05/2012

Aceite em:18/08/2012

Flávia Cristina Silveira Lemos é graduada em Psicologia pela UNESP (1999), Mestrado em Psicologia e Sociedade/ UNESP (2003) e Doutorado em História e Sociedade pela UNESP (2007). Foi bolsista CAPES no mestrado e FAPESP no doutorado. Professora adjunta III de psicologia social, em regime de dedicação exclusiva, na UFPA e bolsista de produtividade CNPQ PQ2. Endereço: PPGP/IFCH-UFPA. Av. Augusto Correa, n. 01. Bairro Guamá, Belém-PA, Brasil. CEP 66000-000. E-mail: flavazevedo@hotmail.com

Hélio Rebello Cardoso Junior é Professor Livre-Docente em Filosofia da Universidade Estadual Paulista Júlio de Mesquita Filho/Assis-SP. Bolsista de produtividade CNPQ PQ2. Concluiu três pós-doutorados, um deles com o prêmio 2008-2009 Fulbright Scholar Program Advanced Research and University Lecturing Awards; o mais recente junto a Universidade de Paris. E-mail: herebell@hotmail.com

Marcos César Alvarez é Sociólogo e desenvolve atividades de ensino, de pesquisa e de extensão relacionadas aos domínios da Sociologia da punição e do controle social, bem como no âmbito da teoria social, das metodologias de pesquisa e do pensamento social no Brasil. Possui graduação em Ciências Sociais (1984), Mestrado (1989) e Doutorado (1996) em Sociologia, todos obtidos na Universidade de São Paulo, e pós-doutorado na École des Hautes Études en Sciences Sociales, Paris (2008-2009).

Professor e orientador no Departamento de Sociologia e no Programa de pós-graduação em Sociologia da USP. Foi assistente de pesquisa no CEBRAP (1985-1986), consultor de pesquisa no Instituto Brasileiro de Ciências Criminais (2009-2010) e pesquisador sênior no Núcleo de Estudos da Violência da USP desde 2004 até o presente. Bolsista de Produtividade em Pesquisa pelo CNPq, nível 1C. E-mail: mcalvarez@usp.br

\section{Como citar:}

Lemos, F. C. S., Cardoso Junior, H. R., \& Alvarez, M. C. (2013). Instituições, confinamento e relações de poder: questões metodológicas no pensamento de Michel Foucault. Psicologia \& Sociedade, 26(n. spe.), 100-106. 